\title{
Best Practices and Current Research in Organizational Training and Performance: An AECT Division of Organizational Training and Performance Special Issue of Tech Trends
}

\author{
Nancy B. Hastings ${ }^{1}$ • Jennifer A. Bauman ${ }^{2}$
}

Published online: 19 December 2016

(C) Association for Educational Communications \& Technology 2016

Much of the research related to the field of Educational Technology focuses on the application of new technologies in traditional educational settings, including K12 schools and higher education. These studies, while valuable, overlook an additional, important, and growing area of practice related to Educational Technology; business, industry and other organizational settings. Globalization and rapid changes in technology have had a tremendous impact on the way we do business, in all businesses, small and large, across all industries. Simultaneously, the increased mobility of today's workforce has led to more rapid turnover in organizations, as new employees come and go, often taking with them critical knowledge, skills and abilities. These changes are fueling an increasing demand for current research and best practices related to organizational training and performance improvement. The Association for Educational Communications and Technology's Division of Organizational Training and Performance is uniquely positioned to fill this need.

The mission of the Association for Educational Communications and Technology's Division of Organizational Training and Performance is to bridge the gap between research and practice, facilitating communication, collaboration and sharing between academics, students and practitioners across multiple

Nancy B. Hastings

nhastings@uwf.edu

Jennifer A. Bauman

JennyBauman@quickenloans.com

1 University of West Florida, Pensacola, FL, USA

2 Quicken Loans, Detroit, MI, USA disciplines interested in applying current theory and research to training and performance improvement initiatives. There are two particularly notable points in this mission. First, the division, like Tech Trends, is focused on bridging the gap between research and practice. This is a critical yet often overlooked aspect of research. We must insure that our research is accessible and applicable beyond the world of academe, insuring that best practices are in fact put into practice. The second point we highlight from the division's mission is the reference to performance improvement initiatives. The inclusion of performance improvement is intentional, focused on reminding us that educational technology encompasses much more than planned instruction. To facilitate lasting change in organizational settings we must employ the performance, gap, and cause analysis techniques associated with Human Performance Technology prior to selecting appropriate interventions, which may or may not include formal instruction.

The articles included in this special issue address a broad range of topics related to current research and best practices in organizational training and performance. Serdar Abaci and James A. Pershing lead off the issue with "Research and Theory as Necessary Tools for Organizational Training and Performance Improvement Practitioners". Jill E. Stefaniak follows with "The Role of Coaching Within the Context of Instructional Design". Next Sung "Pil" Kang focuses our attention on the importance of analysis with "What do HPT Consultants Do for Performance Analysis?". Yonjoo Cho follows with a look at collaboration in "Identifying Interdisciplinary Research Collaboration in Instructional Technology". The remaining articles included in the special issue focus on research and best practices associated with specific types of training and performance improvement initiatives. Julaine M. Fowlin leads off with "Approaching Knowledge 
Management Through the Lens of the Knowledge Life Cycle: A Case Study Investigation". Marc Egloffstein and Dirk Ifenthaler provide "Employee Perspectives on MOOCs for Workplace Learning", which is followed by Wellesley R. Foshay and Judith Hale's article, "Application of Principles of Performance-Based Assessment to Corporate Certifications". We close with "Design Recommendations for Self-Paced Online Faculty Development Courses” by Melissa Rizzuto.
The articles in this special issue represent a small sample of the current research and best practices associated with the application of educational technology in organizational training and performance. Our hope is that they will inspire you to consider the many organizational applications of educational technology, the need for additional research in these areas, and the importance of bridging the gap between research and practice. 